\section{Furanyl-Fentanyl Overdose Events Caused by Smoking Contaminated Crack Cocaine - British Columbia, Canada, July 15-18, 2016}

Salman A. Klar, MPH ${ }^{1}$; Elizabeth Brodkin, $\mathrm{MD}^{1}$; Erin Gibson ${ }^{1}$; Shovita Padhi, MD ${ }^{1}$; Christine Predy ${ }^{2}$; Corey Green, MHSc ${ }^{1}$; Victoria Lee, $\mathrm{MD}^{1}$

On July 15 2016, Surrey Memorial Hospital's emergency department notified the medical health officer on call of a sharp increase in opioid overdose events in Surrey, Fraser Health Authority, in British Columbia, Canada. During July 15-18, the number of persons with suspected opioid overdose evaluated in Surrey Memorial Hospital's emergency department increased approximately $170 \%$, from an average of four suspected cases per day during the period January-June 2016 to 43 (nearly 11 per day) during the 4-day period (Figure). Most patients (22 [51\%]) became unconscious after smoking what they believed to be crack cocaine. The majority of overdose events occurred within a small geographic area in Surrey that has a high population of homeless persons and persons who use illicit drugs, including opioids and crack cocaine. Most cases occurred in males (36 cases [84\%]); the average age of the patients was 42 years (range $=18-63$ years).
Forty $(93 \%)$ patients were brought to the emergency department by ambulance. A total of $37(86 \%)$ patients received injectable naloxone before arriving in the emergency department, including 12 who received it only from community members, 16 who received it only from paramedics, five who received it from both community members and paramedics, one who received it from the fire department and paramedics, and one who received it from the fire department, community, and paramedics; for two patients, the source of naloxone was not known. Reports from first responders, the community, and emergency department staff members indicated that patients required high doses of injectable naloxone, in some cases up to $3.0 \mathrm{mg}$ (usual dose $=0.4 \mathrm{mg}$ ). Thirty-five (81\%) patients were treated and discharged within a few hours, two patients left without being seen by a health care provider, and six patients were admitted to the hospital; among these, three were transferred to the intensive care unit, one of whom died.

Local laboratories do not always have capacity for quantitative fentanyl testing or detection of new analogs. The immunoassay urinalysis testing kits used at the local hospital laboratory (Sure

FIGURE. Number of suspected opioid overdoses $(n=43)$ evaluated at Surrey Memorial Hospital, by time of arrival in the emergency department British Columbia, Canada, July 15-18, 2016

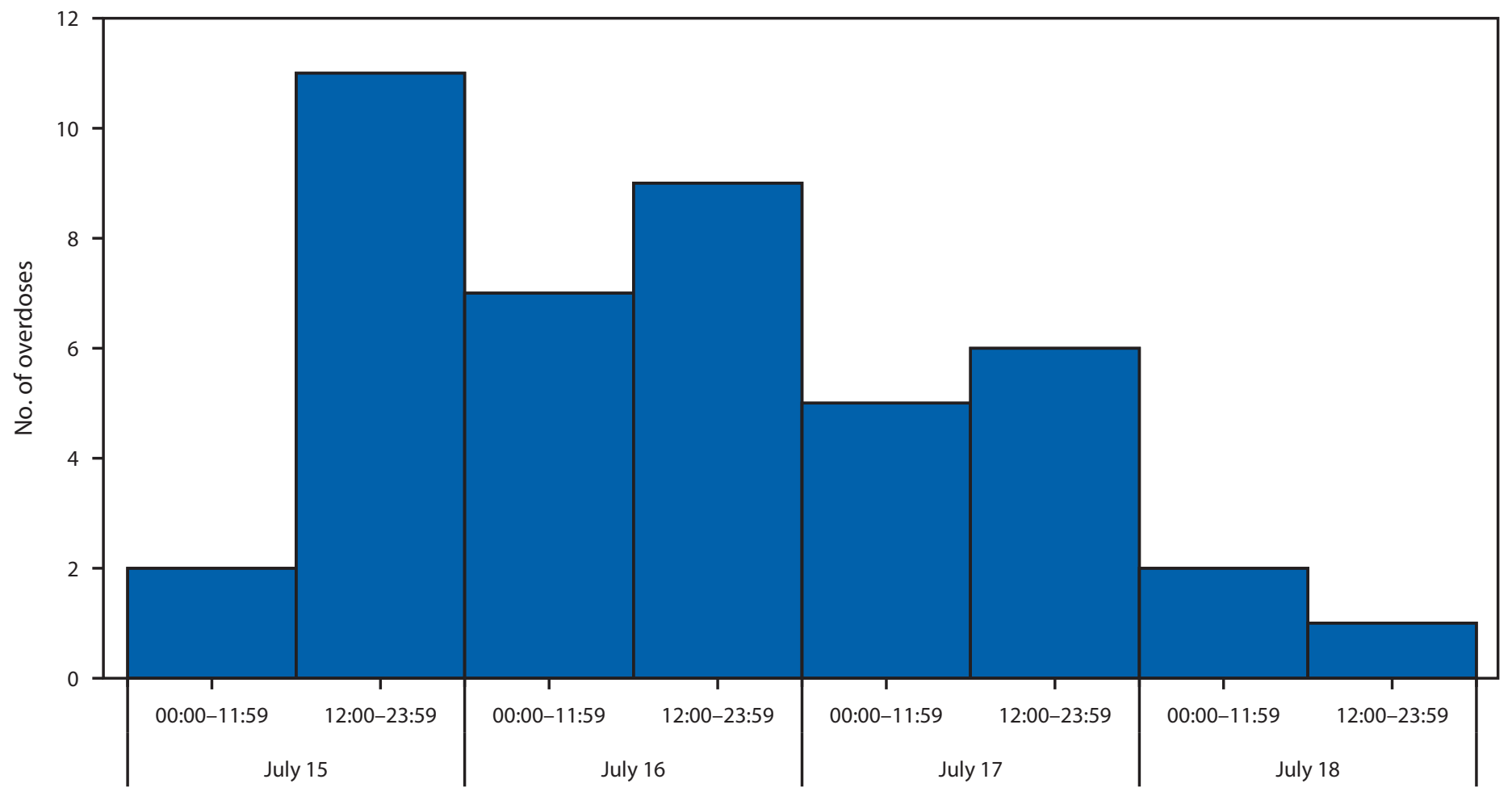

Time (24 hrs)/Date 
Step [Alere Innovacon]) only detect fentanyl and norfentanyl. Therefore, select samples obtained by local police and the hospital were sent to the Health Canada Drug Analysis Service; these tested positive for a combination of furanyl-fentanyl and cocaine.

During July 15-18, Fraser Health Authority, in collaboration with community partners including police and persons who use illicit drugs, distributed warnings throughout the community and organized training sessions on naloxone administration in the affected area. Approximately 100 persons, many at high risk for overdose, were trained and received naloxone kits through the Take Home Naloxone program.*

British Columbia is currently experiencing a public health emergency related to increases in drug-related overdose deaths, especially associated with opioids such as fentanyl. A similar increase has been reported in the United States $(1,2)$, where alerts have been issued regarding fentanyl- and fentanyl analog-adulterated pills, and furanyl-fentanyl has been detected during postmortem examinations $(3,4)$.

Laboratory investigations and community reports at the time of this event indicate that the spike in overdose events likely resulted from a batch of crack cocaine from one dealer, which was adulterated with furanyl-fentanyl, a fentanyl analog that had not previously circulated in this community. Based on reports from patients, community organizations providing services in the area on that weekend, and police, ambulance, and fire services, the substance was consumed by persons who had a longstanding history of drug use but who might not have used opioids regularly. There have been police reports of cocaine contaminated with fentanyl in the neighboring city of Delta (5) and of U.S. overdose events from cocaine contaminated with acetylfentanyl in King County, Washington (6).

This is the first reported cluster of overdose events caused by crack cocaine contaminated with furanyl-fentanyl in North America. Persons who use illicit drugs, health care providers, first responders, and poison control centers should be alert for

\footnotetext{
* http://www.healthlinkbc.ca/healthfiles/hfile118.stm.
}

symptoms of opioid overdose even when the drug consumed is reported to be a nonopioid, such as crack cocaine. Rapid distribution of naloxone kits with training to community organizations and populations at high risk, and provision of naloxone kits to patients evaluated for suspected opioid overdoses in emergency departments, could help mitigate the impact of opioid overdoses.

\section{Acknowledgments}

Staff of the Emergency Department at Surrey Memorial Hospital; British Columbia Ambulance Services; Surrey Fire Service, British Columbia; Surrey Royal Canadian Mounted Police, British Columbia; Drug Overdose Alert Partnership, British Columbia; British Columbia Centre for Disease Control; Health Canada Drug Analysis Service (Burnaby); British Columbia Drug and Poison Information Centre; community organizations and persons who reversed overdoses, and helped with distribution of naloxone kits and health warnings.

\footnotetext{
${ }^{1}$ Population and Public Health, Fraser Health Authority, British Columbia, Canada; ${ }^{2}$ Surrey Memorial Hospital, Fraser Health Authority, British Columbia, Canada.

Corresponding author: Victoria Lee, victoria.lee@fraserhealth.ca, 1-604-587-7891, ext.76789.
}

\section{References}

1. Rudd RA, Aleshire N, Zibbell JE, Gladden RM. Increases in drug and opioid overdose deaths_-United States, 2000-2014. MMWR Morb Mortal Wkly Rep 2016;64:1378-82. http://dx.doi.org/10.15585/mmwr.mm6450a3

2. BC Gov News. Provincial health officer declares public health emergency. Government of British Columbia; April 14, 2016. https://news.gov.bc.ca/ releases/2016HLTH0026-000568

3. Mohr AL, Friscia M, Papsun D, Kacinko SL, Buzby D, Logan BK. Analysis of novel synthetic opioids U-47700, U-50488 and furanyl fentanyl by LC-MS/MS in postmortem casework. J Anal Toxicol 2016. Epub September 1, 2016. http://dx.doi.org/10.1093/jat/bkw086

4. CDC. Health Alert Network: influx of fentanyl-laced counterfeit pills and toxic fentanyl-related compounds further increases risk of fentanyl-related overdose and fatalities. Atlanta, GA: US Department of Health and Human Services, CDC; August 25, 2016. https://emergency.cdc.gov/han/han00395.asp

5. CBCNews. Fentanyl-laced cocaine warning issued by Delta Police after overdoses. December 5, 2015. http://www.cbc.ca/news/canada/british-columbia/ delta-police-warn-of-possible-fentanyl-laced-cocaine-after-overdoses-1.3352815

6. Public Health-Seattle and King County. Acetylfentanyl-laced cocaine may have killed two in King County. June 3, 2016. http://www.kingcounty.gov/ depts/health/news/2016/June/3-acetylfentanyl-laced-cocaine.aspx 